\title{
Discussion on Database Principles Experiment Teaching Reform
}

\author{
Ling-xing Yang ${ }^{1, \text { a }}$ \\ ${ }^{1}$ School of Physics and Electric Engineering, Qujing Normal University, Qujing Yunnan China \\ 655011; \\ a84759653@qq.com
}

Keywords: practical teaching reform,teaching mode,inquiry learning,case teaching method.

\begin{abstract}
Experiment teaching, as an important link of the database principles course, has great significance for cultivating students' abilities demanded for the future work. Considering that the existing experiment teaching method fails to satisfy the contemporary social development demands and is also adverse for development of the electronic information engineering specialty, the experiment teaching reform becomes necessary. Aimed at issues existing in database principles and application of experiment teaching, in this paper, a series of reform measures have been proposed and meanwhile, results acquired relying on implementing teaching reform, such as increase in teaching quality and new ideas provided for the school transformation and development and cultivation of talents serving the local economy, have been summarized.
\end{abstract}

\section{Introduction}

With popularity of computer application and increase in the informationization degree, application of database becomes more and more wide. In these years, many universities have set up courses related to database for students majoring in non-computer specialties. Meanwhile, social development also proposes higher requirements for teaching. With regard to cultivation schemes and cultivation targets, schools have to closely keep up with pace of times, especially cultivating a large number of application-based talents for the society. Therefore, cultivation of practical skills is more important. At present, experiments are also arranged for the database course, but importance attached to it is not enough. During the teaching process, teachers pay more attention to theoretical knowledge. However, such knowledge is relatively abstract, which is difficult for students to understand and then further results in separation between theory and practice. The final result is quite poor teaching effect and the teaching targets cannot be realized. Therefore, the current experiment teaching must be reformed.

\section{Reform of Experiment Teaching Mode}

2.1 Experiment requirements shall be classified into different levels. Because students of the computer specialty have relatively good mathematical foundation, it is easy for them to learn theoretical knowledge related to database. Therefore, more attention could be paid on all contents related to the basic database principles and for experiment requirements, emphasis shall be put on design, management, development and maintenance of database. In addition, for the experiment environment, the database management systems that are widely applied, such as SQL SERVER and ORACLE, could be selected. Meanwhile, the advanced development tools, such as JAVA and Visual Studio.NET, could be combined with so that students could understand methods for access to database and lay a solid foundation for work in the future. However, for students of educational technology specialty, considering low requirements for their theoretical knowledge, Visual FoxPro, ACCESS and other software platforms are more suitable. In other words, there are different specific requirements for different specialties, and such requirements shall demonstrate different knowledge points, key points and difficult points ${ }^{[1]}$. 
2.2Experiment organization manner shall be reformed.In the past, experiments were arranged by teachers and completed by students in the designated laboratory. During such a process, teachers are only responsible for giving simple instructions. At present, such a manner can be adopted that, firstly giving a task and then students independently completing this task strictly according to the development flow of a practical project and communicating with teachers when necessary, which will not occupy learning hours specified by the teaching program. In such a case, students could have time to study knowledge they are interested in to lay a firm foundation for the further employment. Teachers should teach students according to their aptitude and exercise their practical abilities during the experiment process.

2.3Experiment contents shall be implemented in different stages. The current experiment teaching mode is also phased to some extent, but simply and mechanically. The experiment is conducted according to the arrangement of teaching schedule, and the comprehensive experiment is also conducted finally, but the effect is not good at the end of term, and the students cannot design database independently upon graduation. In fact, the key points of each stage which are correlated but not repeated will be reflected in phases. Under normal conditions, the experiment stages of database are divided into: knowledge point verification experiment, chapter summary experiment, knowledge comprehensive experiment, curriculum design, professional practice and graduation design (thesis), etc.. Each stage is a progressive process from simple to complex, the previous stage is the base of the later stage, and the later stage is the sublimation of the previous stage, which is also the process from simple and scattered knowledge to analysis, design and comprehensive application.

\section{Reform and Discussion of Experiment Teaching Method}

3.1Implement case teaching, and cultivate the logical thinking ability of students. Currently, the experiment teaching effect of the curriculum is not satisfying. The main problems are caused by less experiment class hour, simple experiment content, low experiment enthusiasm of student and improper tutorship, etc. This situation must be changed [4]. We require the student can resolve relevant problems with basic knowledge of database, and concretely design and realize database information system. For the students without actual project development experience, the case teaching is the most suitable method. The students can master how the database structure of one function is designed through learning and use of actual system, and it is easier for them to understand the theoretical knowledge.

Firstly, we will consider selecting some typical functions such as score inquiry to explain from educational management system so that the students can understand the database table structure. Secondly, we should make the students make reverse analysis on how to design the database of educational management system to fully exercise the project development ability of students. Finally, we should make the students analyze the problems existing in the educational management system from the points of functional structure and database design structure, further master the theoretical knowledge and analysis and design method of database application system [1], and exercise the logical thinking ability of students.

3.2Combine experiment and scientific research project, and guide students for inquiry-based learning. Besides verifying theoretical knowledge and comprehensive design, the most important aspect of experiment learning is to resolve practical problems by learned knowledge. However, it is difficult to cultivate the ability in this aspect, and the students can take exercise only when they are admitted to the enterprise to participate in project development or take part in scientific research project of teachers. There are no training bases in the school currently, and we can recruit students who are interested in database knowledge to take part in research in scientific research project of teachers.

We should make the students divide the tasks rationally as project managers to cultivate the research and development ability as well as organization and management ability of students. We should make the students independently think and find out approaches to the problems, guide students 
for inquiry-based learning in unknown field, and provide resources or tell students how to obtain resources when necessary, so that the students will learn actively instead of passively [5] and become the leader of experiment, and the tasks are completed independently by students as long as meeting the requirements. In this case, the students can not only learn theoretical knowledge, improve their skill, cultivate the inquiry-based learning ability and practical ability, but also improve their innovation consciousness and innovation ability, and make full preparation for work.

\subsection{Diversification of experiment form.}

3.3.1 Students take part in experiment in groups. Students take part in the traditional experiment together. Because the experiment condition is limited, one lesson will be spent by the teacher explaining the problems of some students, setting examples, and letting students take exercises, however, in which, other students cannot be tutored and their problems cannot be resolved. In this case, the experiment effect is not good, and the students will lose their interest in experiment learning. In order to solve such problem, the measure we should take is to divide students in groups and tutor the students of one group mainly every time, require students of other groups of reporting the experiment content, ask questions or check experiment projects by spot test, organize to discuss the experiment situation, select the excellent experiments for learning of other groups, criticize and educate the students who conduct experiment badly or who do not make independent experiment, and take some measures to avoid this situation.

3.3.2 The emphasis of experiment content is different. Because the grouping experiment is taken, the experiment content and emphasis of each time is different, each group of students should make preparation. However, the experiment content should cover the outline requirement so as to avoid the experiment content repeating. We require each student should complete the experiment content and make summary, apply relevant experiment knowledge to specific actual problems so as to have the design and development ability of general application system database. We should also supervise the students conducting independent experiment for independent learning and mastering experiment content and application. This manner emphasizes that the students having experimental lesson must master the basic experiment requirement, but the students who conduct independent experiment and not tutored by the teacher directly must complete relevant contents. Thus, the teacher select major tutorship without compromise, the students can learn simply, the experiment purpose is also reached, and the effect is better than that of traditional manner.

3.3.3 Based on students-centered, the teacher initiatively tutors them for experiment. The experiment content of database is arranged by the teacher in advance, the teacher tutors students to complete experiment in the classroom, and the students submit the experiment report. However, the teacher is difficult to judge the learning effect of students from experiment report, and the experiment cannot reach to the expected target. On one hand, we should center on students, enlighten students for learning, independent thinking and self-problem solving, and cultivate the independent learning ability of students; on the other hand, the students do not know what to learn and how to learn, and do not know the problems even they have been existing. Under this condition, the teacher should initiatively observe the experiment situation of students [3], inquiry them whether there are doubts, find out their confusion existing in the experiment process, and timely guide, advise and help students to clear up confusion and enter into a good learning state.

3.3.4 Build reasonable evaluation system, and improve experiment teaching quality. The degree of experiment teaching quality cannot be evaluated by classroom teachers and students, the teachers of teaching and researching office and dean's office should also take part in it, make objective evaluations for the teaching situation of teachers, find out the disadvantages of teachers and propose guidance and training, help teachers to improve the experiment teaching method, and improve the experiment teaching quality. We can take the method that students evaluate teachers through more than 30 indexes such as experiment teaching resource, experiment teaching process and experiment teaching result, relatively and objectively gather these indexes to obtain the experiment teaching assessment result of teachers, combine the assessment result with vital interests of teachers, 
so as to mobilize the enthusiasm of teachers, develop the best teaching level, and ensure teaching quality.

\section{Summary}

The teacher should carefully emphasize the importance of experiment in the class of database principle, rationally adjust the experiment requirement on course classroom experiment, course design, comprehensive design, practice on campus and graduation design for students who are not majored in computer, conduct plan and design again, and improve the teaching method. Through experiment of recent three terms, the students not only improve the experiment performance, but also master the theoretical knowledge better than the previous students, especially the passing rate of database system engineer is about $45 \%$, and it is worthy of being praised to obtain the performance for students who are not majored in computer. In addition, the most important aspect is that the students have the independent learning ability, their learning initiative is improved, and they can learn easily in the unknown field at the beginning stage, and can proficiently master the use of database management system through searching data, which is very important for them to take up relevant work in the future.

\section{References}

[1] Hu Daquan, Zhou Yumin and Du Maokang,Reform and Discussion of Database Experiment Teaching of Economic Management Major,J. Experiment Science and Technology, 2009 (10).

[2] Sa Shixuan and Wang Shan, Outline of Database System. Higher Education Press, Beijing, 2006.

[3] Wang Fenge and Zhu Changxing, Reform and Discussion of Experiment Teaching of Principles of Database System,J. Agricultural Network Information, 2010(7).

[4] Wang Tong and Wang Liang, Application of Case Teaching Method in the Course of of Database Principle,J. Computer Education, 2006 (2).

[5] Kong Feng, Reform of Database Course Experiment Teaching Faced to Cultivation of Innovation Ability,J. Chinese Modern Education Equipment, 2010 (23). 